\title{
Mild hyponatremia discovered within the first 24 hours of ischemic stroke is a risk factor for early post stroke mortality
}

\author{
Agnieszka Gala-Błądzińska, ${ }^{1,2, A-E}$, Jolanta Czarnota, ${ }^{3, B-D}$, Rafał Kaczorowski, ${ }^{3, B, C, E}$, \\ Marcin Braun ${ }^{4,5, C, D}$, Krzysztof Gargasz ${ }^{1, C, D}$, Halina Bartosik-Psujek ${ }^{1,3, A, C, E, F}$ \\ 1 Faculty of Medicine, University of Rzeszów, Poland \\ 2 Dialysis Center, St. Queen Jadwiga Clinical District Hospital No. 2, Rzeszów, Poland \\ ${ }^{3}$ Department of Neurology, St. Queen Jadwiga Clinical District Hospital No. 2, Rzeszów, Poland \\ ${ }^{4}$ Department of Pathology, Chair of Oncology, Medical University of Lodz, Poland \\ ${ }^{5}$ Postgraduate School of Molecular Medicine, Warsaw Medical University, Poland \\ A - research concept and design; $\mathrm{B}$ - collection and/or assembly of data; $\mathrm{C}$ - data analysis and interpretation; \\ $D$ - writing the article; $E$ - critical revision of the article; $F$ - final approval of the article
}

Address for correspondence

Agnieszka Gala-Błądzińska

E-mail: agala.edu@gmail.com

\section{Funding sources}

None declared

Conflict of interest

None declared

Received on March 29, 2018

Reviewed on November 3,2018

Accepted on January 21, 2019

Published online on September 13, 2019

Cite as

Gala-Błądzińska A, Czarnota J, Kaczorowski R, Braun M, Gargasz K, Bartosik-Psujek H. Mild hyponatremia discovered within the first 24 hours of ischemic stroke is a risk factor for early post stroke mortality. Adv Clin Exp Med. 2019;28(10):1321-1327. doi:10.17219/acem/103070

DOI

10.17219/acem/103070

Copyright

Copyright by Author(s)

This is an article distributed under the terms of the

Creative Commons Attribution Non-Commercial License

(http://creativecommons.org/licenses/by-nc-nd/4.0/)

\begin{abstract}
Background. Comorbidities, complications and laboratory abnormalities are common in stroke patients. One of the common problems is hyponatremia (serum sodium ( $\mathrm{Na}$ ) level $<135 \mathrm{mmol} / \mathrm{L}$ ), but the relationship between hyponatremia and the prognosis in patients with stroke is not well understood.

Objectives. The aim of this study was to investigate the prevalence and severity of hyponatremia, as well as its impact on prognosis in stroke patients on admission to hospital.

Material and methods. The study involved the analysis of the first measurement of the Na level after the admission and its correlations with comorbidities, the scale of clinical assessment of stroke severity (NHHSS), the size and location of the stroke, and mortality. A retrospective study was conducted on 502 patients (among them 263 women) admitted to the hospital on stroke onset (440 ischemic stroke (IS) and 62 hemorrhagic stroke (HS) patients). The post-stroke mortality was defined as early if death occurred within 30 days.

Results. Hyponatremia was found in $18.4 \%$ of patients with IS and $25.8 \%$ of patients with HS, irrespective of age and gender. Hyponatremia is an independent prognostic factor of mortality in people with IS ( $p=0.003)$. $\mathrm{Na}$ levels were lower in IS patients who died than in those who remained alive $(134.8 \pm 4.99 \mathrm{mmol} / \mathrm{L}$ vs $136.6 \pm 3.01 \mathrm{mmol} / \mathrm{L} ; \mathrm{p}=0.02$ ). Higher mortality rate was observed among $\mathrm{IS}$ patients under 75 years of age and Na level $\leq 132 \mathrm{mmol} / \mathrm{L}$. In patients with $\mathrm{S}$, hyponatremia correlates with NIHSS ( $p=0.005$ ) and the size and location of the stroke $(p=0.002)$.

Conclusions. Hyponatremia is more frequently observed in patients with HS than IS. Mild hyponatremia is already known to be an independent prognostic factor in the mortality of people with IS and it may also have value as a prognostic factor in the mortality of the IS population. In a patient with a suspected stroke, there is a need to control electrolyte levels at the onset of the stroke, especially in patients with comorbidities, irrespective of age.
\end{abstract}

Key words: stroke, hyponatremia, hospital mortality 


\section{Introduction}

Hyponatremia is defined as a decrease in the serum sodium $(\mathrm{Na})$ concentration below $135 \mathrm{mmol} / \mathrm{L}^{1-3}$ It is a common electrolytic disorder diagnosed in patients hospitalized due to different neurological diseases, such as subarachnoid hemorrhage, brain injury and meningitis. ${ }^{4}$ Cardiovascular disorders, including strokes, constitute the cause of half of the deaths of Europeans ${ }^{5}$ and Americans. ${ }^{6}$ In stroke patients, different comorbidities and complications are very common, and there are studies evaluating their impact on neurological condition during the acute phase of stroke, on disability, and on early mortality. ${ }^{7}$

Natremia can be both the cause and the effect of brain damage. As a result of damage to the brain due to a stroke, cerebral salt-wasting syndrome (CSWS) or inadequate secretion of vasopressin (SIADH) may result, resulting in hyponatremia. At the same time, in acute hyponatremia, as a result of the sudden loss of $\mathrm{Na}$ from intravascular fluid and a decrease in the osmolality of the serum, brain cells can swell as a consequence of the passage of water from the vascular bed to the nerve cells because of the higher osmolality of the intracellular fluid. However, if corrected too quickly, chronic hyponatremia may cause osmotic demyelination syndrome and irreversible brain damage. In addition, and as a result of brain damage in the course of a stroke, central diabetes insipidus can occur, resulting in a loss of clean water and hypernatremia. At the same time, we often observe hypernatremia in those stroke patients with accompanying unconsciousness that prevents them from drinking fluids. ${ }^{8,9}$

When examining a patient with a newly diagnosed stroke, the differential diagnosis of hyponatremia should also consider any co-morbidities or pharmacotherapies that may influence or be associated with hyponatremia. ${ }^{1}$ Patients, especially those with ischemic stroke (IS), also often suffer from metabolic syndrome, whose components, such as hyperglycemia, hyperlipidemia and hypertension, can generate hyponatremia per se; this syndrome can also be a result of the patient's pharmacotherapy. In addition, hyponatremia is often associated with other diseases of affluence, such as heart failure or chronic kidney disease. Hyponatremia may also be the result of liver failure, hypothyroidism and adrenal insufficiency, vomiting or diarrhea., ${ }^{4,6}$ The drugs that can often cause hyponatremia include diuretics (in particular thiazides), antidepressants, anticonvulsants (carbamazepine), some cytostatics, and non-steroidal anti-inflammatory drugs., ${ }^{1,9}$

Hyponatremia has been evaluated in only a few studies so far, and a relationship between hyponatremia during the first day of stroke and 30-day mortality has been found. ${ }^{7,10,11}$ However, the cut-off value for natremia below which the mortality increases significantly has not been determined in any previous study. Therefore, we evaluated the correlation between the value of natremia and demographic data, length of hospitalization, and the patient's clinical status on the day of hospital discharge.

The aim of the study was to investigate the prevalence and severity of hyponatremia on the first day of stroke, as well as the relationship between hyponatremia and the consequences of stroke. Special attention was paid to the impact of hyponatremia on mortality.

\section{Material and methods}

A retrospective study involved patients admitted to the Neurology Department of the St. Queen Jadwiga Clinical District Hospital No. 2 in Rzeszów (Poland) from January 1, 2015 to December 30, 2015. The study included 501 stroke patients (263 women and 239 men) admitted to the hospital on the first day of the stroke. On the basis of clinical symptoms and computed tomography (CT) or magnetic resonance imaging (MRI) scans, 440 patients were diagnosed with IS and 62 with hemorrhagic stroke (HS) (Table 1). Patients with hemorrhage related to anticoagulation, trauma, tumor and arteriovenous malformations, or after acute thrombolysis or coagulopathy were excluded. We used the National Institutes of Health Stroke Scale (NIHSS) to assess the severity of stroke symptoms at the time of admission and of discharge. ${ }^{10}$ Also, we used the Paciaroni et al. scale to assess the distribution and size of the IS (Table 3), and the results are presented in Table 4.

On admission to the hospital, all patients underwent laboratory tests including serum electrolyte concentrations. Serum natremia was determined in blood samples collected on a clot, with the indirect potentiometric method with ion selective electrodes using the Beckman Coulter ${ }^{\circledR}$ AU 680

Table 1. Characteristics of stroke patients

\begin{tabular}{|c|c|c|c|c|c|c|}
\hline \multirow{2}{*}{ Variable } & \multicolumn{3}{|c|}{ Ischemic stroke } & \multicolumn{3}{|c|}{ Hemorrhagic stroke } \\
\hline & total & alive & deaths & total & alive & deaths \\
\hline $\begin{array}{l}\mathrm{n}[\%] \\
\quad \text { men, n [\%] } \\
\text { women, n [\%] }\end{array}$ & $\begin{array}{l}440 \\
205 \\
235\end{array}$ & $\begin{array}{l}396(90.0) \\
189(92.2) \\
207(88.1)\end{array}$ & $\begin{array}{l}44(10.0) \\
16(7.8) \\
28(11.9)\end{array}$ & $\begin{array}{l}62 \\
34 \\
28\end{array}$ & $\begin{array}{l}41(67.2) \\
22(64.7) \\
19(67.9)\end{array}$ & $\begin{array}{r}21(33.8) \\
12(35.3) \\
9(32.1)\end{array}$ \\
\hline $\begin{array}{l}\text { Age [years] } \\
\text { median } \\
\text { mean }( \pm S D) \\
\text { range (min-max) }\end{array}$ & $\begin{array}{c}73.0 \\
76 \pm 13.9 \\
24-96\end{array}$ & $\begin{array}{c}72.3 \\
75 \pm 14.0 \\
24-96\end{array}$ & $\begin{array}{c}81.3 \\
83 \pm 9.5 \\
48-99\end{array}$ & $\begin{array}{c}75.4 \\
77 \pm 13.5 \\
24-95\end{array}$ & $\begin{array}{c}73.8 \\
74 \pm 13.8 \\
24-95\end{array}$ & $\begin{array}{c}78.3 \\
82 \pm 12.5 \\
48-94\end{array}$ \\
\hline
\end{tabular}

SD - standard deviation. 
Table 2. Participation of patients with IS and HS depending on the value of natremia

\begin{tabular}{|l|c|c|c|}
\multicolumn{1}{|c|}{ Variable } & $\begin{array}{c}\text { Normonatremia } \\
n[\%]\end{array}$ & $\begin{array}{c}\text { Mild hyponatremia } \\
n[\%]\end{array}$ & $\begin{array}{c}\text { Moderate hyponatremia } \\
n[\%]\end{array}$ \\
\hline Hemorrhagic stroke $(\mathrm{n}=62)$ & $46(74.3)$ & $13(20.9)$ & $2(3.2)$ \\
\hline Ischemic stroke $(\mathrm{n}=440)$ & $359(81.6)$ & $66(15.0)$ & $12(2.7)$ \\
\hline
\end{tabular}

biochemical analyzer (Beckman Coulter, Brea, USA). Hyponatremia was diagnosed if the serum $\mathrm{Na}$ concentration was below $135 \mathrm{mmol} / \mathrm{L}$. For evaluation of the effects of serum hyponatremia on early post-stroke mortality and functional outcome, the first measurements of natremia obtained in the emergency room before any diagnostic or therapeutic intervention were analyzed. Patients diagnosed with hyponatremia were treated according to the etiology, gravity and duration of hyponatremia. The period of 30 days between stroke and death was assumed as a definition of early poststroke mortality. All patients were clinically assessed using the Rankin scale on the day of discharge from the hospital or on day 30 of hospitalization.

\section{Statistical analysis}

The statistical analysis was performed on the basis of paper and electronic medical records. Categorical data was reported as numbers of patients (percentage of the appropriate group). Median (lower-upper quartile) or mean \pm standard deviation (SD) were reported for continuous variables. The analysis was started by checking the normal distribution (Shapiro-Wilk test) and variance homogeneity (Levene's test). A non-parametric MannWhitney $U$ test was performed. For categorical data, the $X^{2}$ test was used. Differences were considered significant at the level of $\mathrm{p}<0.05$. For the receiver operating characteristic (ROC) curve analysis, cut-off values optimizing the Youden index were calculated. To determine better predictability of death based on Na level, a Kaplan-Meier probability of survival was estimated. A multivariate analysis of survival and hyponatremia was performed using Cox's proportional hazard regression model. Statistical calculations were performed using the STATISTICA v. 12 software package (StatSoft Inc., Tulsa, USA).

\section{Results}

The mean Na level was $136.5 \pm 3.26$ (median $=137$, $\min =116, \max =147)$ in IS and $135.9 \pm 3.94($ median $=136$, $\min =118, \max =144$ ) in HS. The differences were statistically nonsignificant. There was no correlation between the age of patients and serum Na concentrations in both the whole population and after distinction between the HS and IS groups. There were no differences in serum $\mathrm{Na}$ concentrations between men and women (Mann-Whitney $\mathrm{U}$ test $\mathrm{p}=0.3$ and $\mathrm{p}=0.2$, respectively). The average length of hospitalization of patients with IS was $17 \pm 23.4$ days
Table 3. Distribution and size of ischemic stroke according to the Paciaroni et al. scale si $^{14}$

\begin{tabular}{|c|c|c|}
\hline $\begin{array}{l}\text { Type } \\
\text { of stroke }\end{array}$ & $\begin{array}{l}\text { The size } \\
\text { of the stroke }\end{array}$ & Range of vascularization \\
\hline 1 & small & $\begin{array}{l}\text { change in front or posterior vascularization } \\
<1.5 \mathrm{~cm}\end{array}$ \\
\hline 2 & average & $\begin{array}{l}\text { change including cortical branches of MCA } \\
\text { change including deep MCA branches } \\
\text { change on the border between } \\
\text { the } 2 \text { territories } \\
\text { change including cortical PCA branches } \\
\text { change including deep PCA branches } \\
\text { change including cortical ACA branches }\end{array}$ \\
\hline 3 & large - front & $\begin{array}{l}\text { change covering the entire range of MCA, } \\
\text { PCA and ACA } \\
\text { change including } 2 \text { cortical MCA branches } \\
\text { change includes cortical and deep MCA } \\
\text { branches } \\
\text { change covering more than } 1 \text { arterial range }\end{array}$ \\
\hline 4 & large - rear & $\begin{array}{l}\text { change involving the brain stem } \\
\text { or cerebellum }>1.5 \mathrm{~cm}\end{array}$ \\
\hline
\end{tabular}

MCA - middle cerebral artery; PCA - posterior cerebral artery; ACA - anterior cerebral artery.

(median $=10.5, \min =1, \max =120)$ and with HS was $7.3 \pm 7.0$ days $($ median $=5, \min =1, \max =30)$. Serum $\mathrm{Na}$ level below $135 \mathrm{mmol} / \mathrm{L}$ was found in 97 (19.3\%) patients with stroke. Hyponatremia was found in 81 patients (18.4\%) with IS and 16 patients (25.8\%) with HS.

On the basis of serum $\mathrm{Na}$ concentrations, hyponatremia was divided into mild (130-135 mmol/L), moderate (125$129 \mathrm{mmol} / \mathrm{L})$ and severe $(<125 \mathrm{mmol} / \mathrm{L})$. The participation of patients depending on the value of natremia in patients with IS and HS is presented in Table 2. Among patients with IS and normo-natremia, mortality was $9 \%(n=31)$, whereas in the group of patients with hyponatremia, mortality was $16 \%(\mathrm{n}=13)$.

Our univariate analyses of patients with IS showed that hyponatremia as well as neurological deficits (estimated using NIHSS), the size and location of the stroke (estimated using the Paciaroni et al. scale ${ }^{14}$ ), patients' ages and comorbidities (such as arterial hypertension, chronic kidney disease, heart failure, and hyperlipidemia) were independent predisposing factors in the early deaths of study group members (Table 4).

Moreover, higher mortality was observed in younger, i.e., under 75 years of age, patients with IS and hyponatremia. In the group of patients under 75 years of age with normo-natremia, mortality was $8.6 \%$ whereas among the same age group with hyponatremia, mortality was $16.0 \%$. The differences were statistically significant 
Table 4. Influence of clinical factors and results of laboratory tests in relation to mortality in patients with IS in single and multivariate analyses

\begin{tabular}{|l|c|c|c|c|c|}
\multicolumn{1}{|c|}{ Variable } & $\begin{array}{c}\text { p-value from } \\
\text { univariate analysis } \\
\text { (log-rank) }\end{array}$ & $\begin{array}{c}\text { p-value from } \\
\text { multivariate analysis } \\
(\text { Cox })\end{array}$ & $\begin{array}{c}\text { Hazard } \\
\text { ratio }\end{array}$ & $\begin{array}{c}\text { Confidence interval } \\
(95 \% \text { CI) }\end{array}$ & Type of the effect \\
\hline NIHSS at admission [points] & $<0.0001$ & $<0.0001$ & 1.15 & $1.09-1.21$ & higher - poor prognosis \\
\hline Age [years] & 0.0003 & 0.0046 & 1.05 & $1.01-1.08$ & older - poor prognosis \\
\hline Arterial hypertension [1/0] & 0.0042 & 0.4416 & 1.33 & $0.64-2.74$ & YES - better prognosis \\
\hline Chronic kidney disease [1/0] & 0.0325 & 0.5088 & 0.73 & $0.29-1.83$ & YES - poor prognosis \\
\hline Heart failure [1/0] & 0.0025 & 0.4992 & 0.79 & $0.39-1.58$ & YES-poor prognosis \\
\hline Hyperlipidemia [1/0] & 0.0313 & 0.3342 & 1.51 & $0.65-3.52$ & YES-poor prognosis \\
\hline Type of stroke [1/0]* & $<0.0001$ & 0.0666 & 0.45 & $0.19-1.08$ & higher-poor prognosis \\
\hline Hyponatremia [1/0] & 0.0034 & 0.8637 & 0.94 & $0.48-1.85$ & YES-poor prognosis \\
\hline NIHSS at dismissal [points] & 0.9985 & NS & NS & NS & NS \\
\hline Sex [male/female] & 0.0593 & NS & NS & NS & NS \\
\hline Obesity [1/0] & 0.5665 & NS & NS & NS & NS \\
\hline Hypothyroidism [1/0] & 0.0897 & NS & NS & NS & NS \\
\hline Atrial fibrillation [1/0] & 0.3417 & NS & NS & NS & NS \\
\hline Diabetes mellitus type 2 [1/0] & 0.3461 & NS & NS & NS & NS \\
\hline
\end{tabular}

NS - nonsignificant variables; NIHSS - National Institutes of Health Stroke Scale; ${ }^{*}$ type of stroke as defined in Table 3.
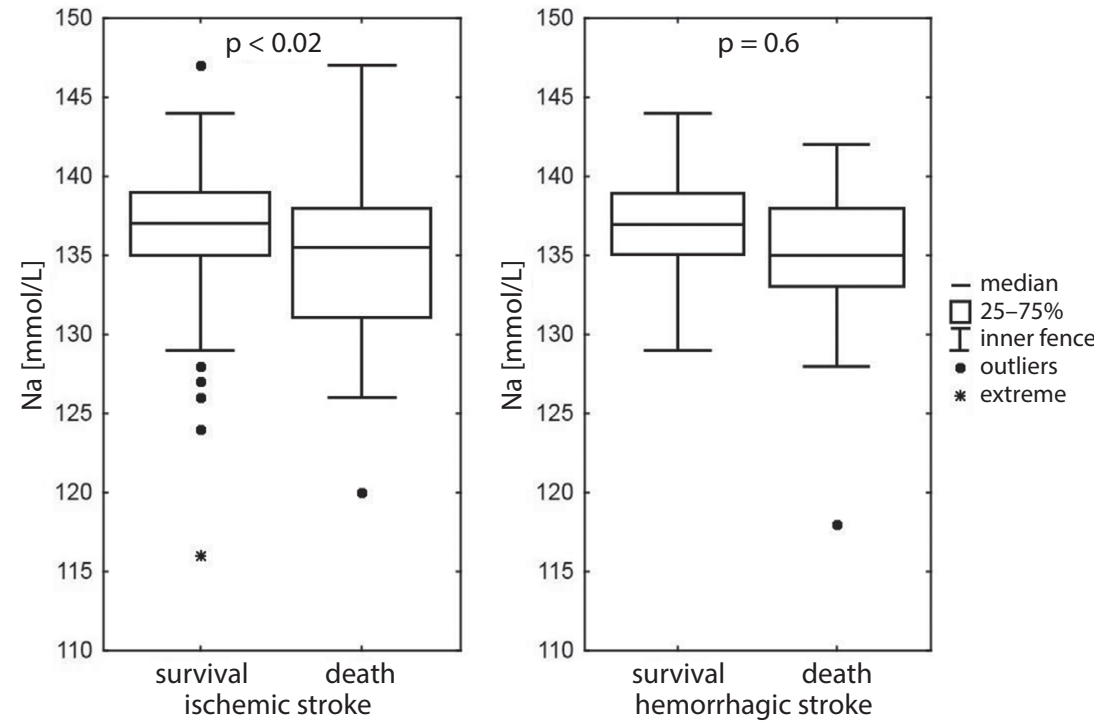

Fig. 1. Effect of natremia on mortality in patients with IS and HS

$\left(\mathrm{X}^{2}\right.$ with Yates's correction $=4.01$; degrees of freedom $(\mathrm{df})=1 ; \mathrm{p}=0.04)$. Sodium levels were significantly lower in those IS patients who died $(134.8 \pm 4.99$; median $=135)$ than in those who remained alive (136.6 \pm 3.01 ; median $=137 ; \mathrm{p}=0.02$; Mann-Whitney $\mathrm{U}$ test with correction for continuity) (Fig. 1).

Sodium levels were lower in patients with HS who died (135.3 \pm 5.18 ; median $=135)$ than in those who remained alive $(136.3 \pm 3.15$; median $=137)$ but

ischemic stroke
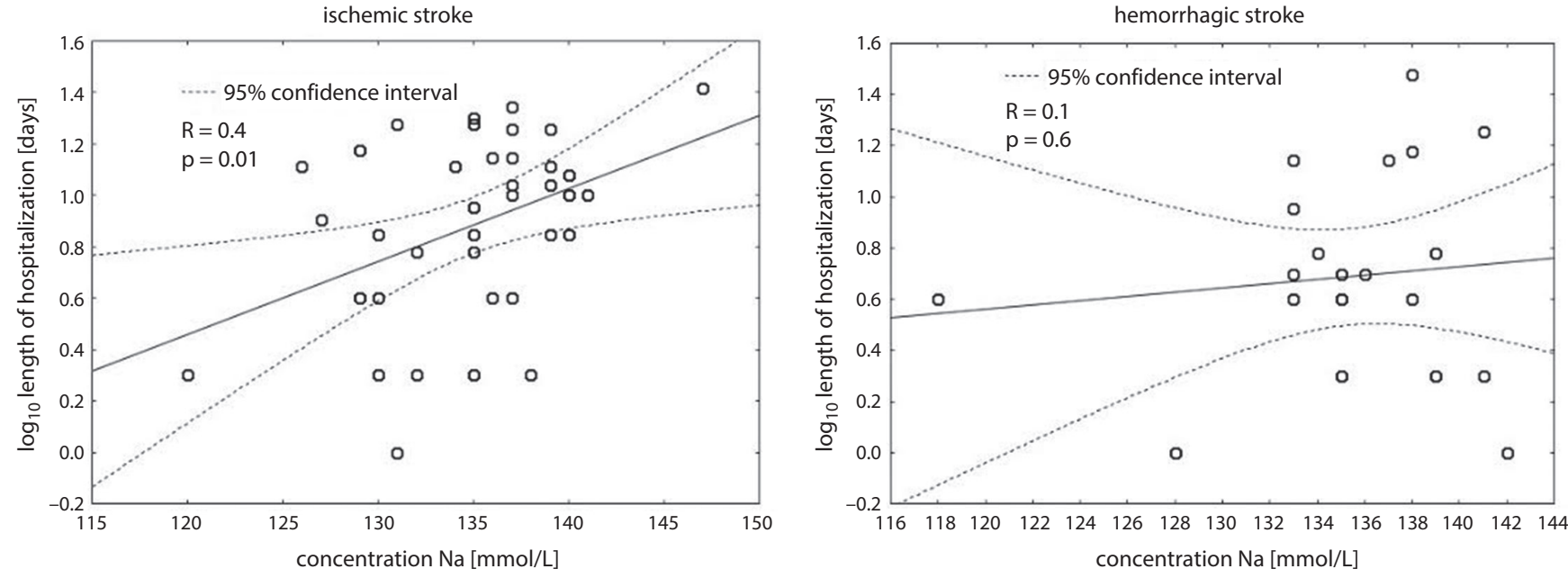

Fig. 2. Relationship between the value of natremia and the survival of IS and HS patients 


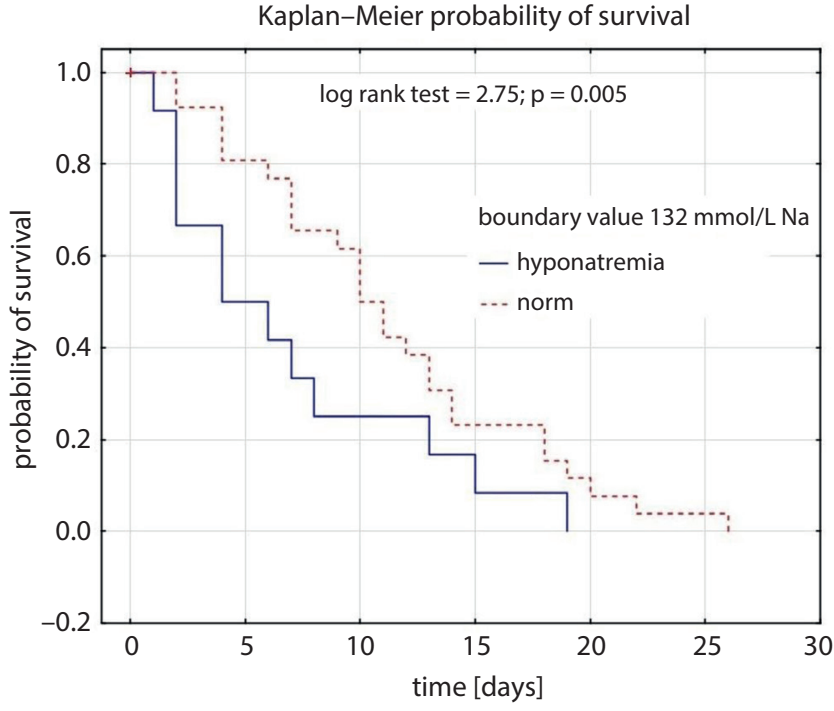

Fig. 3. Survival curve of patients with IS related to the value of natremia

the differences were nonsignificant. Fourteen (30.4\%) patients with HS and normo-natremia died during hospitalization. In the group with HS and hyponatremia $(\mathrm{n}=16), 7(43.7 \%)$ patients died, whereas 9 (56.3\%) were discharged home. However, the relationship was statistically nonsignificant.

Among patients who died in the course of an IS, we showed a statistically significant negative correlation between the length of hospitalization and natremia $(\mathrm{p}=0.01)$. No such correlation was found for HS and hyponatremia (Fig. 2).

On the basis of the single and multifactorial analysis, it was found that in patients with HS there is no statistically significant correlation between their mortality and the coexistence of any of the following: type 2 diabetes, atrial fibrillation, hypertension, heart failure, chronic kidney

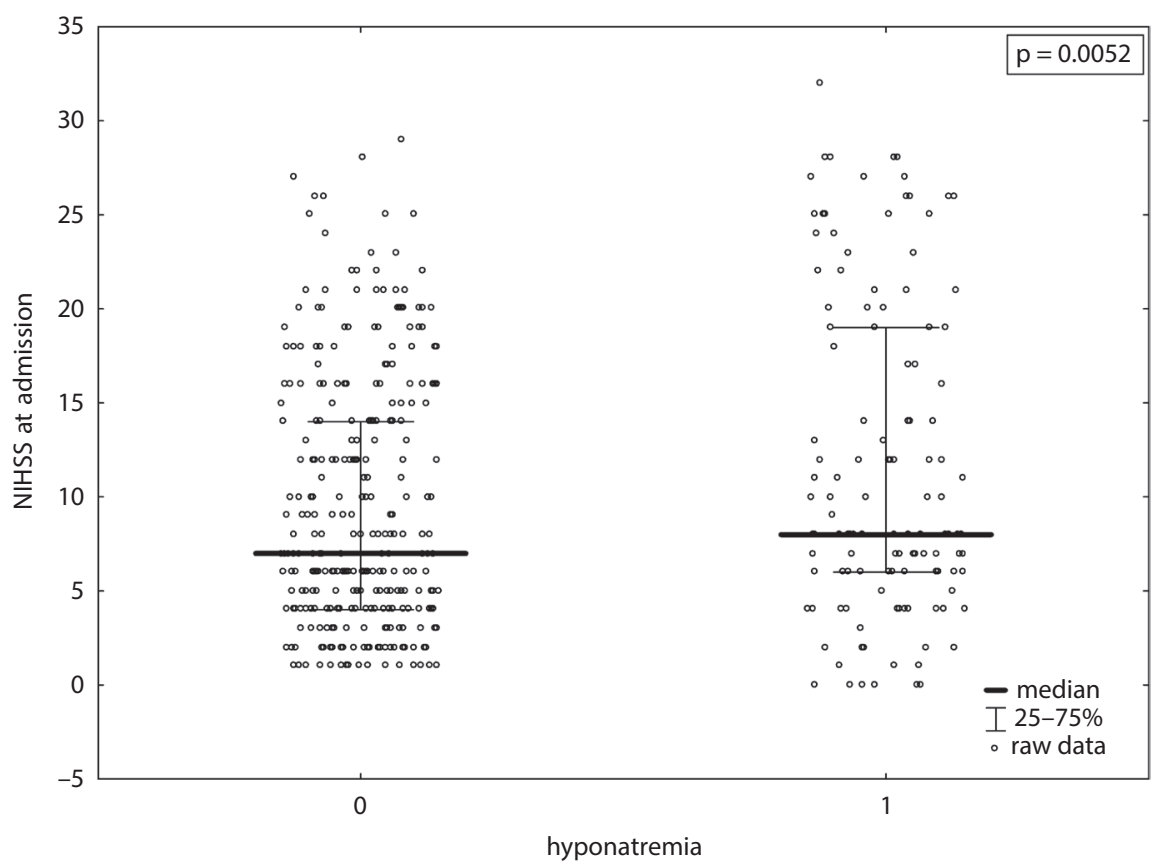

disease, hypothyroidism, obesity, hyperlipidemia, or hyponatremia. In addition, in patients with HS, mortality is not affected by their age or gender. However, patients with HS did have a worse prognosis if they had a higher NIHSS score than other stroke patients when admitted to the hospital $(\mathrm{p}=0.004,95 \%$ confidence interval $(95 \% \mathrm{CI})=1.07-1.28)$. No significant relationship was found between the Rankin scale assessed on discharge from hospital and natremia for all HS population $\left(\chi^{2} \mathrm{NW}=3.66 ; \mathrm{df}=5 ; \mathrm{p}=0.59\right)$ and all IS population $\left(\chi^{2} \mathrm{NW}=4.16 ; \mathrm{df}=5 ; \mathrm{p}=0.52\right)$.

The ROC curve for $\mathrm{Na}$ concentration in the IS group was calculated as area under curve (AUC) $=0.616(95 \%$ $\mathrm{CI}=0.508-0.724) \mathrm{Z}=2.107 ; \mathrm{p}<0.03$. Next, the cut-off point that best discriminated the group in terms of death was determined $(132 \mathrm{mmol} / \mathrm{L})$. This new parameter was used to recalculate survival curves. At a value of Na concentration $\leq 132 \mathrm{mmol} / \mathrm{L}$, there is a statistically significant difference between the survival probability curves for patients with IS who died within 30 days of hospitalization (log-rank $=2.75 ; \mathrm{p}=0.005$ ) (Fig. 3).

As a result of the multivariate analysis, we found that there was a significant relationship between hyponatremia observed on the first day of IS and the clinical status of the patients when evaluated using the NIHSS scale (Fig. 4), assessment of the size and location of the stroke assessed using the Paciaroni et al. scale ${ }^{14}(p=0.002)$ and the observed co-occurrence of atrial fibrillation ( $\mathrm{p}=0.04)$. These dependencies were not found in HS.

\section{Discussion}

Our observation indicates that stroke frequently coexists with hyponatremia, i.e., in over $18 \%$ and $25 \%$ of cases of IS and HS, respectively. In the study by Gray et al., hyponatremia was observed in $24 \%$ of patients with IS during the entire hospitalization period, ${ }^{2}$ whereas in the study by Kuramatsu et al., the percentage of patients with IS and concurrent hyponatremia was $15.3 \% .^{3}$ In our study, the rate of patients with IS and hyponatremia diagnosed on hospital admission was $18.4 \%$, which is a slightly higher value than presented in the works mentioned above. One reason for this observation may be the fact that the patient population in our study was considerably older (76 \pm 13.9 years) compared to the populations studied by Gray et al. and Kuramatsu et al. $(69.8 \pm 13.6$ years and $59.4 \pm 12.1$ years, respectively). ${ }^{2,3}$ An increase in the severity of hyponatremia

Fig. 4. Correlation of hyponatremia and IS in patients' NIHSS clinical scores on admission 
along with patient's age is observed in clinical practice and may be associated with higher comorbidity and polypragmasia. ${ }^{14}$ Moreover, in the population studied, the mean hospitalization time of patients with IS was longer by approx. 10 days. Therefore, it may be concluded that the health status and prognosis in the population of IS patients were worse.

In our study, when we assessed patients with IS who were in a worse clinical condition than other patients using the NIHSS scale at admission, hyponatremia was more often observed. These observations are consistent with the results of Rodrigues et al. ${ }^{15}$ The presence of a positive correlation between the patient's NIHSS assessment which is based solely on physical examination, with a natremia laboratory test result, provides useful information for the clinician wishing to make a prognosis. At the same time, we proved that the location and size of the stroke site, as shown using the Paciaroni et al. scale, also has a significant influence on the emergence of hyponatremia in patients with IS. In our study, in the group of patients with IS the mortality rate in individuals with hyponatremia was 1.8 times higher than in those with normo-natremia. This correlation is statistically significant. We also observed a trend to increase the 30-days mortality in patients with HS and hyponatremia, but it was statistically nonsignificant. These trends are consistent with the research by Kuramatsu et al. ${ }^{3}$

In patients with IS, we found they had a higher risk of death in the following situations: if their clinical status on the NIHSS scale was worse than other patients; if they were older than others; if they had chronic kidney disease, heart failure or hyperlipidemia; or if they received a higher score on the Paciaroni et al. scale. ${ }^{13}$ The unfavorable influence of these clinical factors and abnormalities in laboratory tests on the prognosis of patients with IS is widely known. ${ }^{11,16}$ Some other studies also indicate that the concurrence of hyponatremia and IS at the onset of the disease extend the time of hospitalization. ${ }^{2}$ However, in our population of those IS patients with hyponatremia who died, no correlation with the length of hospital stay was observed, which may be due to the relatively small size of the group studied. In this study, in the IS population, a significant, over 2 -fold, increase in mortality was observed in the group of patients with hyponatremia found at hospital admission compared to the patients with normo-natremia. Our study has confirmed that the mortality of patients with IS and hyponatremia is significantly higher than in patients with normal natremia $(p=0.02)$. Similar observations were made by other authors. ${ }^{4,10,11,15}$ Moreover, we noticed that the severity of hyponatremia found at hospital admission determined the length of survival in patients with IS.

Additionally, we observed that $\mathrm{Na}$ concentration $\leq 132 \mathrm{mmol} / \mathrm{L}$ diagnosed on the first day of IS is a risk factor for mortality within 30 days of stroke onset. This finding is the first in the literature available, and it appears to be important for clinicians. Therefore, if a patient with natremia of $132 \mathrm{mmol} / \mathrm{L}$ or lower is admitted to the neurology department due to IS, particularly careful monitoring should be applied due to the increased risk of early stroke-related mortality. Moreover, in a study conducted by Soiza et al. in patients hospitalized due to IS or HS, hyponatremia in acute stroke admissions is independently associated with higher mortality in patients below 75 years of age. ${ }^{10}$ Our study confirms this unexpected finding regarding increased mortality in the group of younger patients. It has been established that high blood pressure, high cholesterol, smoking, obesity, and diabetes are the leading causes of stroke. In the $21^{\text {st }}$ century, these disorders significantly affect the condition of blood vessels, leading consequently to mortality due to cardiovascular problems. ${ }^{6}$ Increased mortality due to IS in the younger population requires a detailed analysis of the causes of the observed epidemiology in future studies. Special attention should be paid to comorbidities, as they can significantly worsen the prognosis in this group of patients. In our study, the coexistence of heart failure and IS has proved to be a significant and independent risk factor in the emergence of hyponatremia. However, in a study by Huang et al., among the risk factors for stroke, diabetes and renal failure were found to be significantly higher among patients with hyponatremia. ${ }^{11}$

Nevertheless, our study has several shortcomings. First, its retrospective single-center design did not allow us to answer the question why hyponatremia showed increased in-hospital mortality. Second, this is a preliminary study and it evaluates only the relationship between hyponatremia and the clinical condition of patients. Few prospective studies regarding the effect of hyponatremia on prognosis in stroke are available. One of them was conducted by Saleem et al., but its results are difficult to assess since hyponatremia was defined as serum Na concentration below $130 \mathrm{mmol} / \mathrm{L}$, and the time of the assessment of natremia relative to the onset of the disease was not provided. ${ }^{13}$ A prospective, well-designed and preferably multicenter study should be performed on the relationship between hyponatremia and its comorbidities, as well as laboratory parameters. This would allow identification of the causes of pathophysiological changes leading to hyponatremia and prognosis in patients after stroke.

\section{Conclusions}

Hyponatremia is more frequently observed in patients with HS than IS. Mild hyponatremia is already an independent prognostic factor in the mortality of people with IS and $\mathrm{Na}$ concentrations in blood serum may be a predictor of mortality in IS. In addition, and importantly for the clinician, hyponatremia correlates with the clinical condition of the patient and with the size and location of the stroke in patients with IS. Hence, in a patient with 
a suspected stroke, there is a need to control electrolyte levels at the onset of the stroke, especially in patients with comorbidities, irrespective of age.

\section{ORCID iDs}

Agnieszka Gala-Błądzińska (1) https://orcid.org/0000-0001-6617-0852 Rafał Kaczorowski (i) https://orcid.org/0000-0002-8377-7960 Marcin Braun (1) https://orcid.org/0000-0003-3804-7042

Krzysztof Gargasz (i) https://orcid.org/0000-0002-0863-2630 Halina Bartosik-Psujek (1) https://orcid.org/0000-0002-2860-6456

\section{References}

1. Kim DK, Joo KW. Hyponatremia in patients with neurologic disorders. Electrolyte Blood Press. 2009;7(2):51-57.

2. Gray JR, Morbitzer KA, Liu-De Ryke X, Parker D, Zimmerman LH, Rhoney $\mathrm{DH}$. Hyponatremia in patients with spontaneous intracerebral hemorrhage. J Clin Med. 2014;3(4):1322-1332.

3. Kuramatsu JB, Bobinger $T$, Volbers $B$, et al. Hyponatremia is an independent predictor of in-hospital mortality in spontaneous intracerebral hemorrhage. Stroke. 2014;45(5):1285-1291.

4. Lasek-Bal A, Holecki M, Kret B, Hawrot-Kawecka A, Duława J. Evaluation of influence of chronic kidney disease and sodium disturbances on clinical course of acute and sub-acute stage first-ever ischemic stroke. Med Sci Monit. 2014;20:1389-1394.

5. The Global Status Report on Noncommunicable Diseases 2011. Editors: World Health Organization; 2011.

6. Benjamin EJ, Blaha MJ, Chiuve SE et al. American Heart Association Statistics Committee and Stroke Statistics Subcommittee. Heart disease and stroke statistics 2017 update: A report from the American Heart Association. Circulation. 2017;135(10):e229-e445.
7. Karlinski MA, Bembenek JP, Baranowska A, Kurkowska-Jastrzebska I, Czlonkowska A. Noninfectious complications of acute stroke and their impact on hospital mortality in patients admitted to a stroke unit in Warsaw from 1995 to 2015. Neurol Neurochir Pol. 2018;52(2): 168-173.

8. Cuesta M, Hannon MJ, Thompson CJ. Diagnosis and treatment of hyponatremia in neurosurgical patients. Endocrinol Nutr. 2016;63(5): 230-238.

9. Podestà MA, Faravelli I, Cucchiari D, et al. Neurological counterparts of hyponatremia: Pathological mechanisms and clinical manifestations. Curr Neurol Neurosci Rep. 2015;15(4):18.

10. Soiza RL, Cumming K, Clark AB, et al. Hyponatremia predicts mortality after stroke. Int J Stroke. 2015;10(Suppl A):100:50-55.

11. Saleem S, Yousuf I, Gul A, Gupta S, Verma S. Hyponatremia in stroke. Ann Indian Acad Neurol. 2014;17(1):55-57.

12. Brott $\mathrm{T}$, Adams $\mathrm{HP} \mathrm{Jr}$, Olinger $\mathrm{CP}$, et al. Measurements of acute cerebral infarction: A clinical examination scale. Stroke. 1989;20(7):864-870.

13. Paciaroni M, Angeli G, Corea F, et al. Early hemorrhagic transformation of brain infarction: Rate, predictive factors, and influence on clinical outcome. Stroke. 2008;39(8):2249-2256.

14. Rodrigues B, Staff I, Fortunato G, McCullough LD. Hyponatremia in the prognosis of acute ischemic stroke. J Stroke Cerebrovasc Dis. 2014;23(5):850-854.

15. Huang WY, Weng WC, Peng Tl, et al. Association of hyponatremia in acute stroke stage with three-year mortality in patients with firstever ischemic stroke. Cerebrovasc Dis. 2012;34:55-62.

16. Félix-Redondo FJ,Consuegra-SánchezL, Ramírez-Moreno JM, Lozano L, Escudero V, Fernández-Bergés D. Ischemic stroke mortality tendency (2000-2009) and prognostic factors. ICTUS Study-Extremadura (Spain). Rev Clin Esp (Barc). 2013;213(4):177-185. 